\title{
Dual Band Slotted Printed Circular Patch Antenna With Superstrate and EBG Structure for 5G Applications
}

\author{
BISMAH HASAN*, AND KAMRAN RAZA* \\ RECEIVED ON 21.10.2017 ACCEPTED ON 25.05.2018
}

\begin{abstract}
Slotted circular printed layered patch antenna is designed, simulated and fabricated for 5 G (Fifth Generation) wireless communication applications. The antenna consists of slots in the main radiating circular patch element for miniaturizing the size of the radiating element and providing dual band radiation characteristics. The feed line is separated on bottom substrate layer with EBG (Electromagnetic Band-Gap) embedded for enhancing the gain characteristics of the antenna. Superstrate layer is also used for improving the gain of the antenna where the distance from the radiating antenna element is optimized for maximizing the impedance bandwidth and radiation characteristics. The feed realization and impedance matching of the radiating slotted circular patch antenna is done by inducing slot at the middle ground plane of the slot embedded circular patch antenna system. The proposed configuration provides power radiation gain values of more than $5 \mathrm{~dB}$ for the Ka band of communications, whereas the impedance bandwidth of the antenna is verified for the dual resonances at 27.5 and $28.5 \mathrm{GHz}$. Dual band radiation characteristics are attained by embedding and optimizing the slot length and width in the circular patch radiator element that is placed on the upper face of the substrate RT Rogers Duroid 5880 layer. The length of the microstrip feed line embedded in the lower layer of the substrate is optimized for providing required bandwidth characteristics for the dual frequency point radiations. The antenna configuration is designed, modeled and simulated in CST (Central Standard Time) Microwave studio. The antenna is fabricated and measured vs simulated frequency response, gain patterns and current density plots are presented for the verification of antenna operation in the desired frequency bands.
\end{abstract}

Key Words: Dual Band, Patch Antenna, Electromagnetic Band-Gap, Superstrate.

\section{INTRODUCTION}

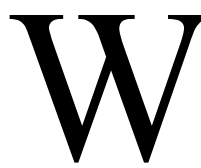

ireless communications with latest trends of high data rate requirements and growth in the use of portable devices pose a challenge for higher system bandwidth and enhanced channel capacity. These modern system specifications can be realized with the advent of $5 \mathrm{G}$ communication system that provides solution for the growing data traffic. The mitigation of increased path loss effects and higher frequency communications of the $5 \mathrm{G}$ systems can be attained by designing antenna systems with various techniques. Dual feed radiator can be designed in loop configuration for $5 \mathrm{G}$ communications 
by using multiple feeds and maintaining conventional pattern characteristics of the loop antenna and also minimizing the network losses between receiver and transmitter [1]. Wide band radiation characteristics can be achieved for $5 \mathrm{G}$ systems by using tapered slot radiating element fed by substrate integrated feeding line with multiple beam characteristics for MIMO (Multiple Input Multiple Output) communications [2]. High gain printed antennas provide suitability for the $5 \mathrm{G}$ systems for compensating path losses by using four element arrays that are designed by triangular shaped slots embedded in substrate fed by integrated feeding microstrip feeding lines [3]. Antenna systems can be designed for simultaneously supporting both $4 \mathrm{G}$ and $5 \mathrm{G}$ standards by combining MIMO antenna systems with array of slot radiating elements covering the $2100 \mathrm{MHz}$ frequency band for $4 \mathrm{G}$ and $28 \mathrm{GHz}$ for $5 \mathrm{G}$ systems respectively [4].

ANN (Artificial Neural Networks) allows calculations of the antenna dimensions for accurately modeling the slot antenna radiation and polarization characteristics that provides suitability for MIMO systems for the $5 \mathrm{G}$ networks [5]. Low side lobe antenna arrays are designed for achieving low cross polarization levels by substrate integrated feeding lines and tapered $\mathrm{T}$ junction dividers suitable at $28 \mathrm{GHz}$ for $5 \mathrm{G}$ systems [6]. Electromagnetic exposures for radiations at higher frequencies that are required for the fifth generation systems can be analyzed by the power density function instead of specific absorption rates and using various configurations of array antennas [7]. Wideband antenna with reduced losses and high gain is designed by using dipole antenna based on magneto electric properties and excited by waveguide integrated coupled slot line where the gain is enhanced by stacking additional substrate layers [8].
Side lobe levels of more than $-18 \mathrm{~dB}$ can be achieved that are suitable for fifth generation communication systems by using linear array of 7 elements and parasitic patch elements coupled through stacked substrate at 28 $\mathrm{GHz}$ frequency band [9]. Phased array beam steering antenna for three dimensional radiations coverage can be design for $5 \mathrm{G}$ applications at $28 \mathrm{GHz}$ by using three arrays of slot radiator based elements and switching between the arrays provides larger coverage area along with enhanced bandwidth [10].

Wireless Communications provides many challenges for the designers in terms of lower cost systems, greater coverage area and high gain requirements. EBG structures provide various benefits in providing enhancement in antenna characteristics for wireless communication. EBG can be used for providing reduction in radar cross section by using layered configuration based on checkboard structures [11]. Gaussian beam is utilized for concentration the radiation along a direction which is achieved by coupling EBG and periodic slow structures [12]. The high mutual coupling between monopole radiating elements for MIMO systems is reduced by incorporating layered EBG for UWB (UltraWide Band) applications [13]. Dielectric resonator antennas are used in wireless communication applications by different researchers due to high efficiency and low loss characteristics with comparison to conventional metallic patches. For exciting HEM11 mode of Dielectric resonator antenna, the dielectric resonator can be placed above a metallic bottom ground plane with some dielectric substrate and it can also be placed without any substrate. For exciting the mode of TM1 1 other than HEM11 dielectric resonator mode, the excitation is done in the region between the copper ground plane and the circular dielectric resonator. The antenna is not categorized as dielectric resonator antenna 
family but rather considered as dense dielectric patch antenna when it is excited in this mode and reflected as part of the patch antenna category. Apart from retaining a low profile trait, the efficiency of this type of antenna at higher frequencies is estimated to be better than normal traditional metallic patch antenna as the efficiency of the conventional patch antenna becomes less at higher frequencies [14]. Gain enhanced antenna array system is essential at Millimeter wave frequency ranges for overcoming the degradation in the signal strength due to oxygen molecular absorption. One of the main techniques for gain enhancement is by using efficient antenna array system where radiation from the feed network can be isolated form the main radiating antenna elements [15]. In addition, for additional gain augmentation superstrate technology can be used [1617]. Gain enhancement is achieved by placing dielectric substrate with an approximation thickness of $0.25 \lambda$ above the radiator at a spacing of $0.5 \lambda$ for getting multiple reflections for the radiating element. Superstrate layer acts as a lens where all the radiations from the main beam are focused in one particular direction that results in a considerable gain enhancement in the antenna.

Coplanar waveguide fed slotted three arms for achieving bandwidth from 5.75-14.51 GHz using artificial magnetic conductor for wideband applications [18]. EBG is used for achieving reconfigurability in terms of polarization and frequency tuning at broadband by using metallic patch arrays [19]. For improving the width of the band gap, an EBG structure is presented in [20], consisting of tapered Koch fractal structures.

EBG can be employed for achieving lower pass band attenuation and stopband below - $20 \mathrm{~dB}$ [21], where the pass band ripples are reduced by Chebyshev tapering and defected ground plane structure is used for enhancing stopband bandwidth characteristics. EBG structures can be used for millimeter wave wireless communication applications [22] for reduced mutual coupling for array antennas based on miniaturized EGB cells at $60 \mathrm{GHz}$. Circularly polarized antenna is designed by using linearly polarized EBG antenna with layer of meander line polarizer from 29.5-30 GHz with less than 1 $\mathrm{dB}$ axial ratio is achieved [23]. Matching devices can be incorporated for compensating degraded axial ratio [24], by using iris based matching system and self-polarized EBG structure centered at $9 \mathrm{GHz}$ providing $20 \mathrm{~dB}$ gain. The radiator can be embedded within EBG for better efficiency and characteristics [25]. Multimode and multibands can be simultaneously attained by using mushroom like EBG [26], where omnidirectional as well as patch like radiation patterns are achieved for the various bands and modes are realized by tuning various parameters of EBG. The comparison summary for various antenna designs suitable for $5 \mathrm{G}$ systems is shown in Table 1.

In this paper a novel layered slotted antenna is presented with the feed line on the bottom layer and the radiating slotted circular patch is placed on a separate top layer. The feeding is done through a slot in the middle ground plane that is between the two substrate layers. The length and width of the slot is optimized for impedance matching and maximum bandwidth of the proposed slotted circular printed patch antenna. Novel EBG is embedded on the bottom substrate layer of Rogers 5880 for improving the gain characteristics. Proposed antenna is made further directional by using superstrate layer whose distance from the radiating antenna layer is optimized. EBG structure details are presented. The simulation of the 
proposed slotted circular layered antenna is done in CST Microwave Studio for frequency response, gain and current distribution plots for the verification of the operation of the antenna for $5 \mathrm{G}$ applications.

\section{SLOTTED CIRCULAR LAYERED PRINTED ANTENNA DESIGN}

The proposed novel slotted circular patch antenna with layered superstrate and ground plane is shown in Fig. 1. The slotted circular printed patch antenna along with the superstrate and EBG embedded bottom layer is optimized for operation of the antenna at $28 \mathrm{GHz}$ for $5 \mathrm{G}$ applications. The top superstrate layer consists of substrate Rogers 5880. The thickness of the substrate Rogers 5880 is 0.508 $\mathrm{mm}$ with dielectric constant of 2.2. The purpose of this layer is to enhance the gain characteristics of the proposed slotted layered circular printed patch antenna. The second layer consist of radiating slotted circular patch antenna etched on a substrate layer of Rogers 5880 as shown in Fig. 1. The radiating element consists of the copper cladding with a thickness of $0.035 \mathrm{~mm}$. The separation of the superstrate layer and the second radiating slotted circular printed patch antenna layer is optimized for providing maximum gain enhancement. The slot embedded in the printed radiating antenna element provides the size reduction in the overall size of the circular printed patch antenna. The bottom side of the second substrate layer of Rogers 5880 consists of the copper ground plane with copper cladding of $0.035 \mathrm{~mm}$. For feeding the circular slotted radiating copper element through a microstrip transmission line etched in the bottom side of the third

TABLE 1. COMPARISON OF SLOTTED CIRCULAR LAYERED PATCH ANTENNA WITH 5G AND EBG BASED ANTENNAS IN LITERATURE VS MAXIMUM GAIN

\begin{tabular}{|c|c|c|c|}
\hline$[1]$ & Rogers RO3003 & $23 \times 15$ & 3 \\
\hline$[2]$ & Rogers RT5880 & $30 \times 8$ & 9.6 \\
\hline$[3]$ & Rogers RT5880 & $23 \times 22.4$ & 13.5 \\
\hline$[4]$ & Rogers RO3003 & $60 \times 30$ & 8.2 \\
\hline$[5]$ & Rogers RT5880 & $24 \times 15$ & 6.8 \\
\hline$[6]$ & Rogers RO4350B & $70 \times 63.5$ & 13.97 \\
\hline [7] & Rogers RT5880 & $40 \times 5.7$ & 12 \\
\hline$[8]$ & Rogers RO3003 & $27 \mathrm{x} 41$ & 15 \\
\hline [9] & Taconic TLY-5 & $96 \times 20$ & 14 \\
\hline$[10]$ & Nelco N9000 & $42.3 \times 10.5$ & 8 \\
\hline$[11]$ & Rogers RT5880 & $112 \times 112$ & 10 \\
\hline$[13]$ & FR4 & $60 \times 50$ & 5 \\
\hline$[18]$ & FR4 & $50 \times 80$ & 10.65 \\
\hline$[22]$ & Rogers RO3006 & $25 \times 20$ & 8 \\
\hline$[26]$ & Rogers RT5880 & $70 \times 70$ & 6 \\
\hline Proposed Work & Rogers RT5880 & $20 \times 20$ & 9.35 \\
\hline$[1]$ & Rogers RO3003 & $23 \times 15$ & 3 \\
\hline
\end{tabular}

Mehran University Research Journal of Engineering \& Technology, Volume 38, No. 1, January, 2019 [p-ISSN: 0254-7821, e-ISSN: 2413-7219] 
substrate, slot is embedded in the middle copper ground plane. The slotted line cut in the ground plane whose length and width are optimized for achieving the proper matching of the feed line with the radiating circular copper slotted patch antenna. The length and width of the slotted cut in the ground plane is also optimized for providing maximum impedance bandwidth for the operating of the antenna. The slot cut is provided in the copper cladding plane with the placement just beneath the radiating circular slotted patch antenna for radiation and efficiency of the antenna element. The feed line is etched at the bottom side of the third substrate of Rogers 5880. One end of the line is soldered with the SMA connector and the other end of the line is open ended.

The length of the line is optimized for providing feeding to the radiating slotted patch antenna element placed at the top substrate layer. The microstrip transmission line width is optimized for providing impedance matching of 50 ohms with the SMA connector. The EBG layer is placed along the microstrip transmission line on the bottom side

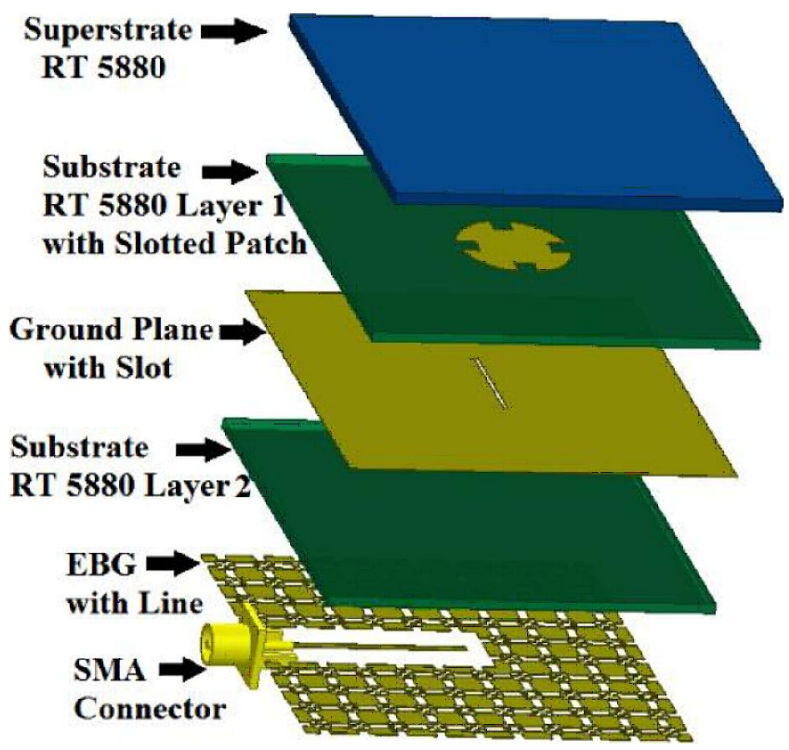

FIG. 1. LABELED DIAGRAM OF THE PROPOSED SLOTTED CIRCULAR PATCH ALONG WITH THE EBG GROUND PLANE AND SUPERSTRATE LAYER of the third Rogers 5880 substrate. The EBG structure provides improved radiation characteristics. The overall size of the EBG layer and the unit cells are optimized for providing radiations in the same frequency bands of 27.5 and $28.5 \mathrm{GHz}$ for the specifications of slotted circular printed radiating antenna element.

The single element of the circular patch antenna is designed by specifying the height of the substrate $h$, frequency of operation $f_{\mathrm{r},}$ and dielectric constant of the substrate $\varepsilon_{\mathrm{r}}$, and calculating a using [27]:

$$
\mathrm{a}=\frac{\mathrm{F}}{\left\{1+\frac{2 \mathrm{~h}}{\pi \varepsilon}\left[\ln \left(\frac{\pi \mathrm{F}}{2 \mathrm{~h}}\right)+1.7726\right]\right\}^{1 / 2}}
$$

Where

$$
\mathrm{F}=\frac{8,791 \times 10^{9}}{\mathrm{f}_{\mathrm{r}} \sqrt{\varepsilon_{\mathrm{r}}}}
$$

The detailed dimension diagram of the slotted circular patch radiator top layer embedded with EBG and transmission line bottom layer and middle copper ground slotted line layer is shown in Fig. 2. The top radiating slotted circular printed patch element dimensions diagram is presented in Fig. 2(a). Both the length and width of the substrate is optimized at $20 \mathrm{~mm}$. The diameter of the circular printed patch antenna is optimized at $5.74 \mathrm{~mm}$. The slots are introduced in the radiating patch antenna as shown in Fig. 2(a) with its length and width optimized at $0.96 \mathrm{~mm}$ and $1 \mathrm{~mm}$ respectively. With these slots the overall size of the radiating element is reduced, as it provides increase in the overall electrical length of the radiating circular printed antenna element. The dimension layout of the middle ground plane with the embedded slotted line is shown in the Fig. 2(b). The slotted line is cut in the ground place with its placement for feeding the radiating element at the middle. The length and width of ground plane is the same as that of the substrate of $20 \mathrm{~mm}$. 
The slot line length and width is optimized at 5.6 and $0.2 \mathrm{~mm}$ respectively. The bottom substrate layer with EBG structure and microstrip feed line dimensions layout is shown in Fig. 2(c). The microstrip transmission feed line in connected to the SMA connector from one end and the other end is terminated right at the middle of the slot placed at the middle

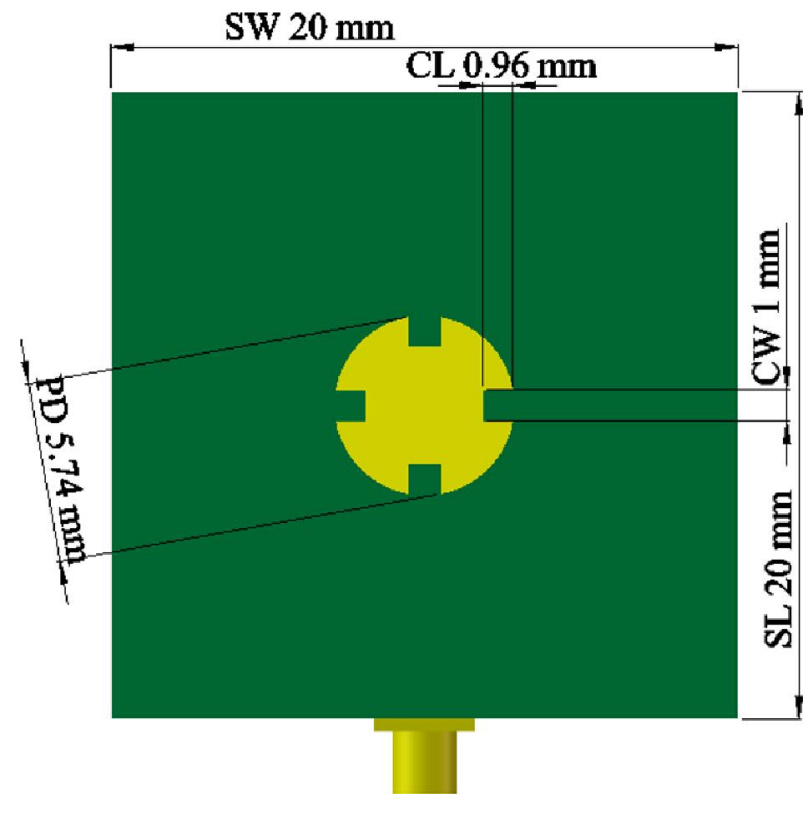

(a) TOP LAYER ground plane. The length and width of the microstrip feed line is optimized at 11 and $0.37 \mathrm{~mm}$ respectively. Whereas the substrate length and width of the bottom Rogers 5880 layer is same as that of the top substrate layers having the dimension of $20 \mathrm{~mm}$. The dimensions of the proposed slotted layered printed circular patch antenna are summarized in Table 2.

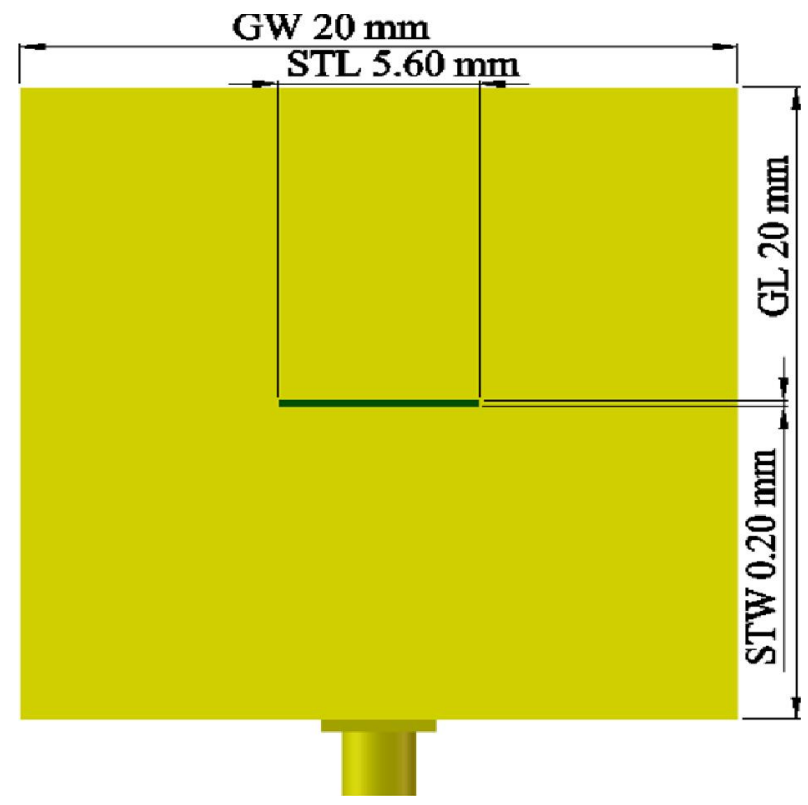

(b) MIDDLE LAYER

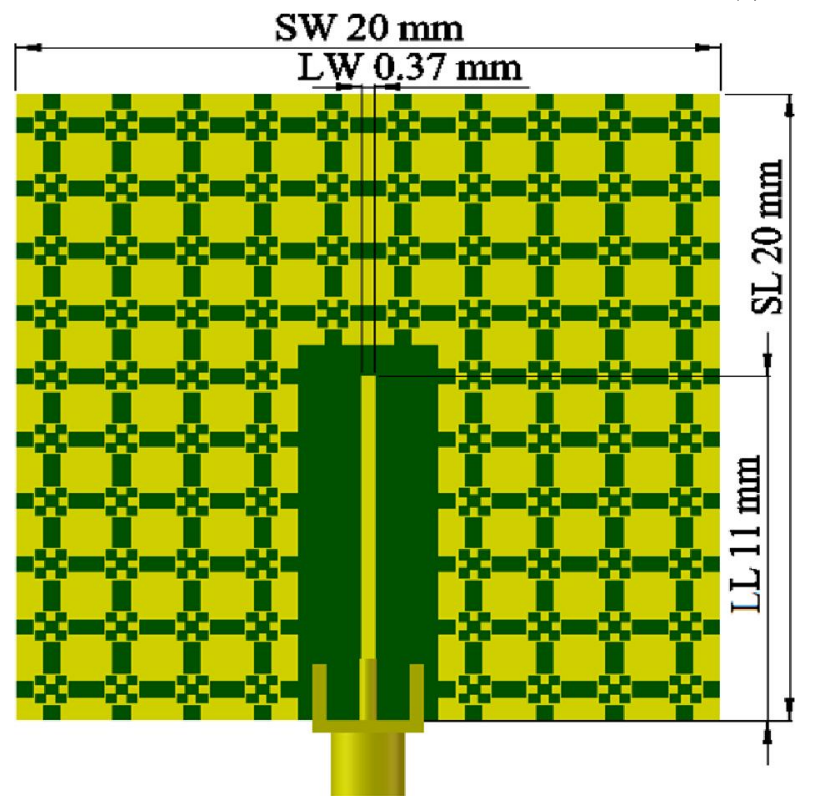

(c) BOTTOM LAYER

FIG. 2. DIMENSIONS DIAGRAM OF THE PROPOSED SLOTTED PRINTED CIRCULAR LAYERED ANTENNA 
The radiated power of the cavity model is expressed as [27]:

$P_{\text {rad }}=\left|\mathrm{V}_{0}\right|^{2} \frac{\left(\mathrm{k}_{0} \mathrm{a}_{\mathrm{e}}\right)^{2}}{960} \int_{0}^{\pi / 2}\left[\mathrm{r}_{02}^{2}+\cos ^{2} \theta \mathrm{J}_{02}^{2}\right] \sin \theta$ in

Where the radiated power is based on the fields formulated as:

$E_{\theta}=-j \frac{k_{0} a_{e} V_{0} e^{-j k_{0} r}}{2 r}\left\{\cos \varphi r_{02}\right\}$

$E_{\varphi}=-j \frac{\mathrm{k}_{0} \mathrm{a}_{\mathrm{e}} \mathrm{V}_{0} \mathrm{e}^{-\mathrm{jk} 0^{\mathrm{r}}}}{2 \mathrm{r}}\left\{\cos \theta \operatorname{os} \theta \varphi \mathrm{J}_{02}\right\}$

And the current densities are given by:

$\mathrm{J}_{02}^{\prime}=-\mathrm{J}_{0}\left(\mathrm{k}_{0} \mathrm{a}_{\mathrm{e}} \sin \theta\right)-\mathrm{J}_{2}\left(\mathrm{k}_{0} \mathrm{a}_{\mathrm{e}} \sin \theta\right)$

$\mathrm{J}_{02}=\mathrm{J}_{0}\left(\mathrm{k}_{0} \mathrm{a}_{\mathrm{e}} \sin \theta\right)+\mathrm{J}_{2}\left(\mathrm{k}_{0} \mathrm{a}_{\mathrm{e}} \sin \theta\right)$

Where $\mathrm{a}_{\mathrm{e}}$ is the effective radius of the circular patch and $\mathrm{k}_{0}$ is the propagation constant.

\section{SIMULATIONAND ANALYSIS}

The proposed slotted circular printed patch radiator is designed and optimized in CST Microwave Studio. The dual band measured vs simulated $\mathrm{S} 11$ frequency response of the slotted circular EBG based antenna is presented in Fig. 3. The optimization of the slotted printed circular layered patch antenna along with the EBG plane is achieved by tuning the slot length and width induced beneath the radiating element in the ground plane layer. The transmission line length and width placed at the bottom of the third Rogers 5880 substrate is also optimized for impedance matching and maximum bandwidth characteristics of the radiating antenna element. As shown in Fig. 3, the slotted circular printed layered patch antenna is optimized to operate in the $\mathrm{K}_{\mathrm{a}}$ Band with center frequency at 27.646 and $28.156 \mathrm{GHz}$ with insertion loss of -13.589 and $-15.779 \mathrm{~dB}$ respectively for $5 \mathrm{G}$ applications. The bandwidth of the proposed slotted printed circular patch antenna system at the two resonance frequency points provides the impedance bandwidth of 309 and 501 MHz.

TABLE 2. SLOTTED CIRCULAR LAYERED PATCH ANTENNA LABELS, DESCRIPTIONS AND DIMENSIONS

\begin{tabular}{|c|c|c|}
\hline Label & Description & Dimensions (mm) \\
\hline PD & Patch Diameter & 20.00 \\
\hline SL & Substrate Width & 00.00 \\
\hline SW & Substrate Length & 00.96 \\
\hline CL & Patch Slot Length & 20.00 \\
\hline CW & Patch Slot Width & 20.00 \\
\hline GL & Ground Length & 05.60 \\
\hline GW & Ground Width & 00.20 \\
\hline STL & Slot Length & 11.00 \\
\hline STW & Slot Width & 00.37 \\
\hline LL & Line Length & \\
\hline LW & Line Width & \\
\hline
\end{tabular}

Mehran University Research Journal of Engineering \& Technology, Volume 38, No. 1, January, 2019 [p-ISSN: 0254-7821, e-ISSN: 2413-7219] 
The parametric analysis of the printed slotted antenna with various lengths of the feed line and embedded circular patch slot length are presented in Figs. 4-5 respectively. The gain vs frequency plot of the slotted printed circular layered patch radiator is demonstrated in Fig. 6, over the whole frequency band. The plot shows the gain characteristic of the antenna from $26-30 \mathrm{GHz}$, with the gain of more than $3 \mathrm{~dB}$ from $26.5-29.5 \mathrm{GHz}$ with a band of $4 \mathrm{GHz}$, and a gain of more than $5 \mathrm{~dB}$ from $27-29.1 \mathrm{GHz}$ covering a frequency band of $2.1 \mathrm{GHz}$. For the frequency band of 27.483-28.452 GHz the impedance bandwidth of less than $-10 \mathrm{~dB}$ insertion loss, the gain of the proposed slotted circular printed layered patch antenna is more than $7 \mathrm{~dB}$. The peak gain in this band is of $9.29 \mathrm{~dB}$ at 27.765 $\mathrm{GHz}$, while at $27.48 \mathrm{GHz}$ the antenna exhibits gain of 7.24 $\mathrm{dB}$ and at $28.48 \mathrm{GHz}$ frequency resonance the antenna demonstrates gain of $7.92 \mathrm{~dB}$. At the center frequency of the proposed printed circular slotted layered patch antenna of $28 \mathrm{GHz}$, the antenna has a gain of $8.03 \mathrm{~dB}$. Thus by using the proposed layered configuration the antenna exhibits an increase in the gain characteristics.

The 3D gain pattern plots of the proposed circular printed slotted printed layered patch radiator are demonstrated in Fig. 7. As seen from the four plots over the frequency band covering the frequency points of 27.48, 27.76, 28 and $28.48 \mathrm{GHz}$, the shape of the radiation pattern remains directional with a gain of more than $7 \mathrm{~dB}$ throughout the frequency band. The surface current plots of the proposed slotted circular printed layered patch antenna along with the microstrip transmission feed line and EBG at the bottom of the ground plane is shown in Fig. 8. The surface currents are plotted for the frequencies of 27.48 and $28 \mathrm{GHz}$ as shown in Fig. 8(a-b) respectively. As seen from the surface currents, for the antenna to be effectively

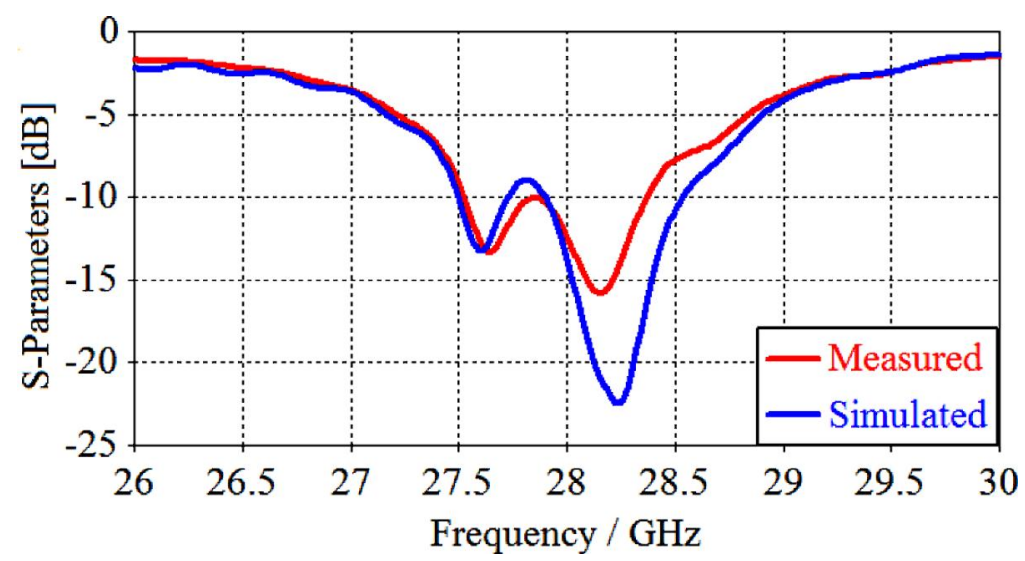

FIG. 3. MEASURED VS SIMULATED FREQUENCY RESPONSE OF THE SLOTTED PRINTED CIRCULAR LAYERED ANTENNA ELEMENT

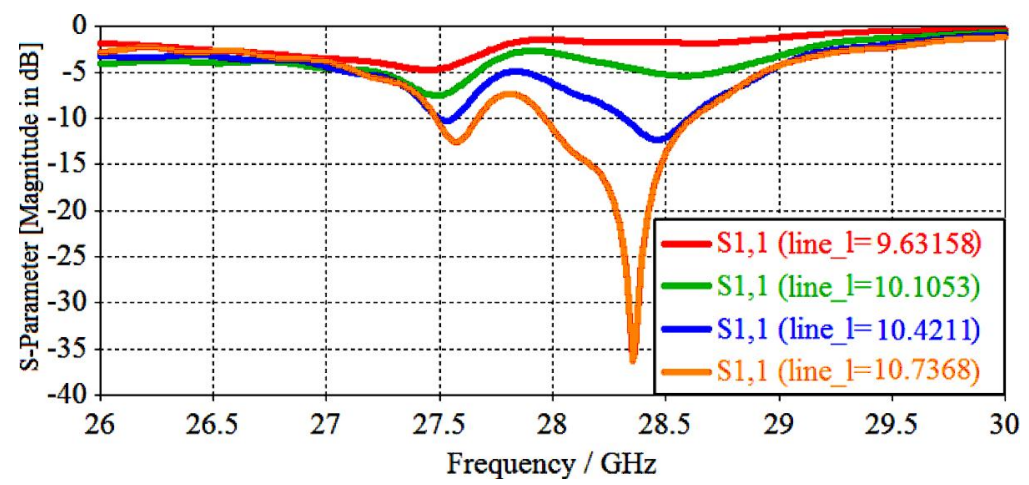

FIG. 4. PARAMETRIC ANALYSIS FREQUENCY RESPONSES OF SLOTTED CIRCULAR ANTENNA FOR VARIOUS FEED LINE LENGTHS IN MM

Mehran University Research Journal of Engineering \& Technology, Volume 38, No. 1, January, 2019 [p-ISSN: 0254-7821, e-ISSN: 2413-7219] 
radiating at $28 \mathrm{GHz}$, the antenna element has strong current distribution at the outer radius of the slotted circular printed patch antenna, with the EBG place at the ground plane and the feeding line also having strong current distributions enhancing the overall gain characteristics of the proposed antenna. The proposed antenna is fabricated and radiation patterns are measured that is presented in Figs. 9-10 respectively.

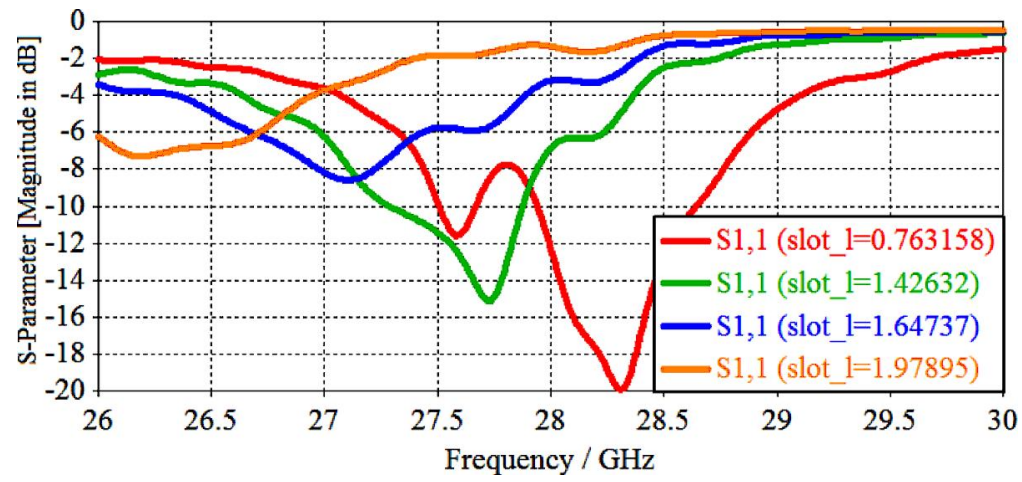

FIG. 5. PARAMETRIC ANALYSIS FREQUENCY RESPONSES OF SLOTTED CIRCULAR ANTENNA FOR VARIOUS CIRCULAR PATCH EMBEDDED SLOT LENGTHS LENGTHS IN MM

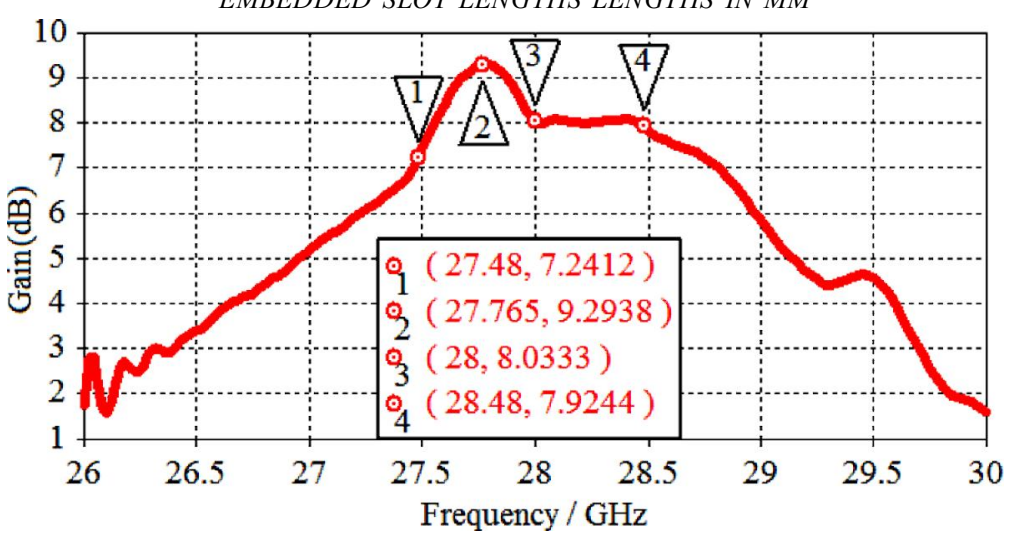

FIG. 6. GAIN VS FREQUENCY PLOT OF THE SLOTTED CIRCULAR PRINTED LAYERED PATCH ANTENNA ELEMENT

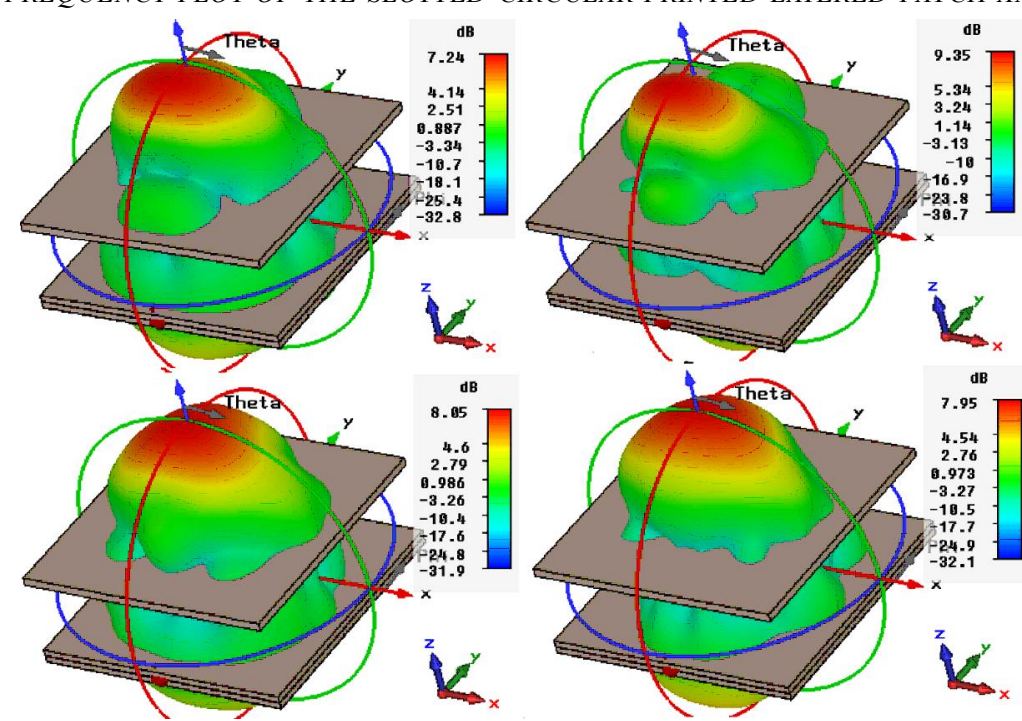

FIG. 7. 3D GAIN PLOTS OF THE PROPOSED SLOTTED PRINTED CIRCULAR LAYERED ANTENNA ELEMENT AT FREQUENCIES, (A) $27.48 \mathrm{GHZ}$, (B) 27.765, (C) $28 \mathrm{GHZ}$, (D) $28.48 \mathrm{GHZ}$ 


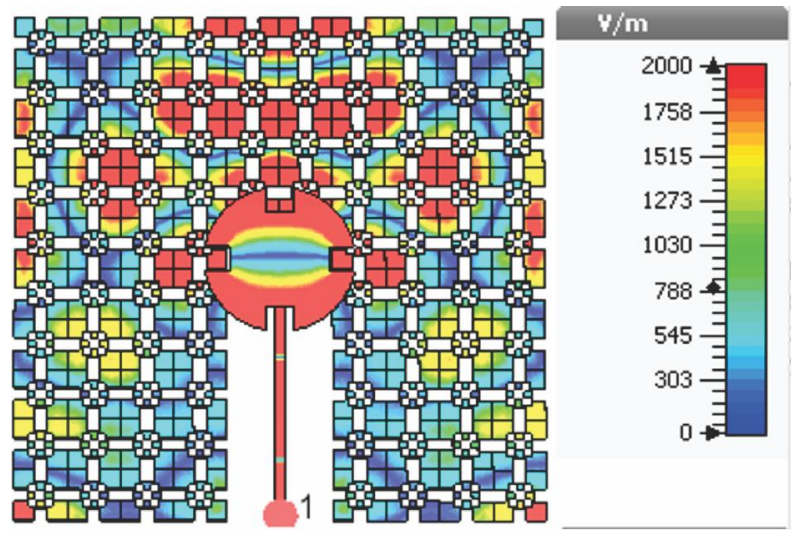

(a) $27.48 \mathrm{GHz}$

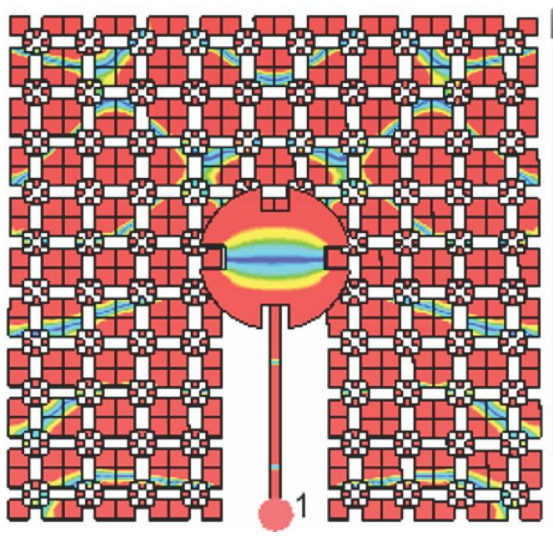

(b) $28 \mathrm{GHz}$

FIG. 8. SURFACE CURRENTS OF THE PROPOSED SLOTTED PRINTED CIRCULAR LAYERED PATCH ANTENNA AT FREQUENCIES

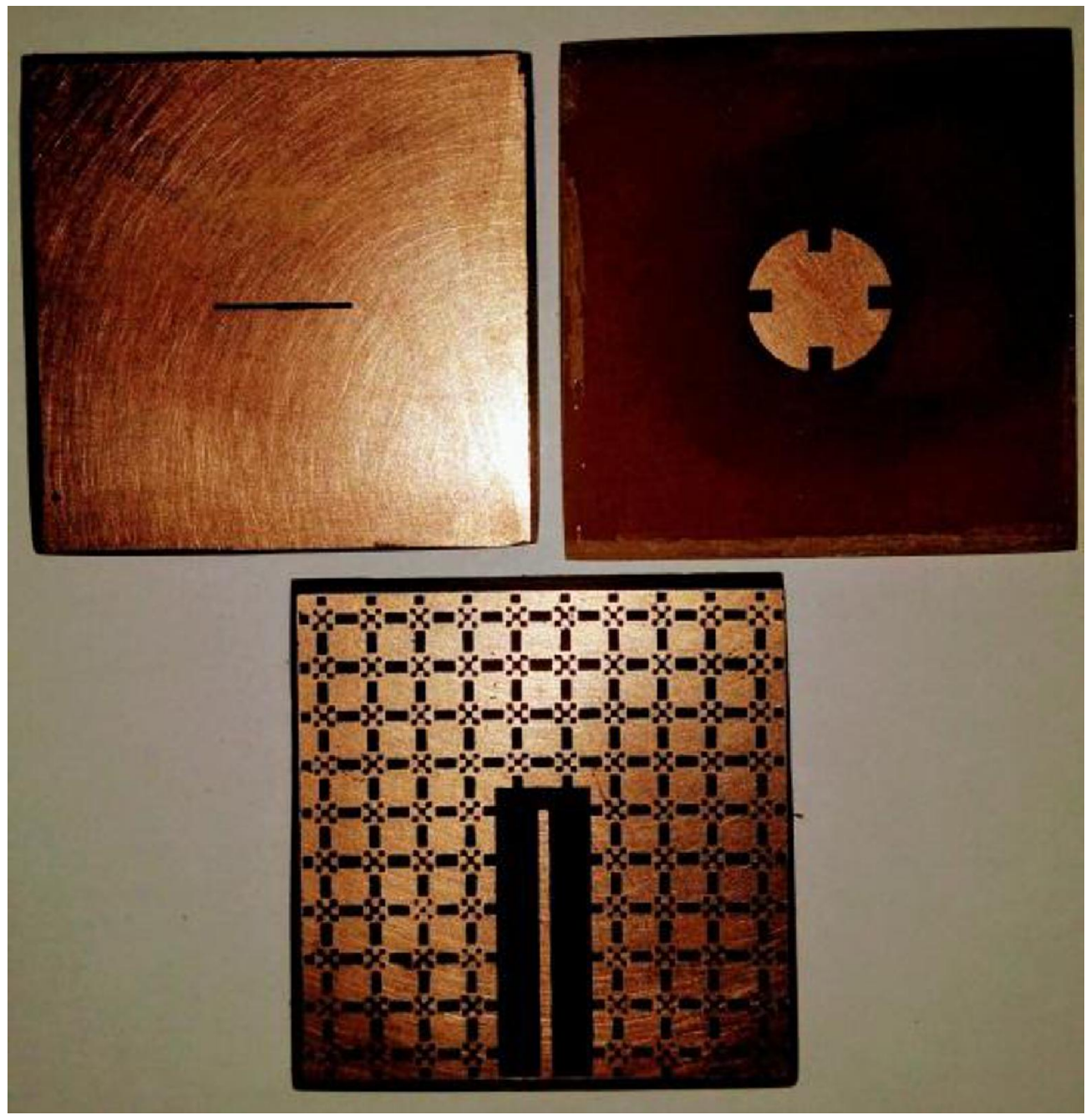

FIG. 9. FABRICATED PROTOTYPE OF THE PROPOSED ANTENNA WITH RADIATING ELEMENT, SLOT LINE AND EBG GROUND PLANE LAYERS

Mehran University Research Journal of Engineering \& Technology, Volume 38, No. 1, January, 2019 [p-ISSN: 0254-7821, e-ISSN: 2413-7219] 


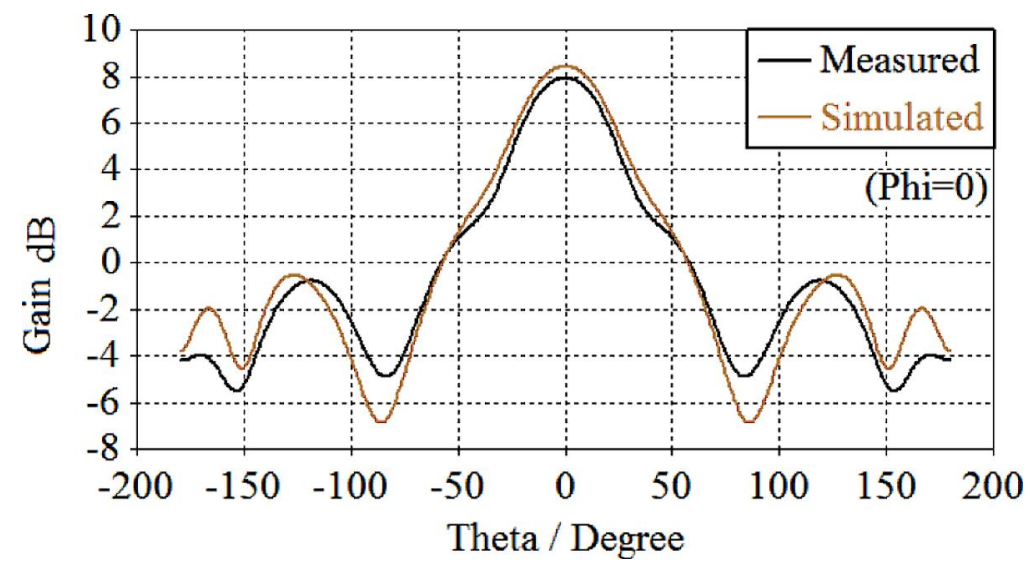

FIG. 10. MEASURED AND SIMULATION 2D RADIATION PATTERNS FOR THE PROPOSED ANTENNA AT 28 GHZ

\section{CONCLUSION}

Slotted circular printed layered patch antenna is proposed having gain enhanced characteristics. The proposed antenna is constructed having layered topology with a superstrate top layer and EBG and feed line embedded in the bottom substrate layer of Rogers 5880 having dielectric constant of 2.33. The proposed antenna is modeled, designed and analyzed in CST Microwave Studio for $5 \mathrm{G}$ applications. The frequency response and surface current plots are verified for the operation of the antenna in the $28 \mathrm{GHz}$ frequency band. The ground slot length and width is optimized at 5.6 and $0.2 \mathrm{~mm}$ for impedance matching of the proposed slotted circular patch antenna. The overall band of antenna is enhanced to $969 \mathrm{MHz}$ with the combination of bottom EBG and top superstrate substrate layers. The printed antenna operates at $28 \mathrm{GHz}$ with gain of more than $8 \mathrm{~dB}$ which is suitable for $5 \mathrm{G}$ applications.

\section{ACKNOWLEDGEMENT}

Authors would like to acknowledge M/S Omar Masood Khan, and Muhammad Khalid, Faculty of Engineering Sciences \& Technology, Iqra University, Karachi, Pakistan, for invaluable discussions and feedback.

\section{REFERENCES}

[1] Li. S., Chi, T., Wang, Y., and Wang, H., "A MillimeterWave Dual Feed Square Loop Antenna for 5G Communications", IEEE Transactions on Antennas and Propagation, Volume 65, No. 12, pp. 6317-6328, December, 2017.

[2] Yang, B., Yu, Z., Dong, Y., Zhou, J., and Hong, W., "Compact Tappered Slot Antenna Array for 5G Millimeter-Wave Massive MIMO Systems", IEEE Transactions on Antennas and Propagation, Volume 65, No. 12, pp. 6721-6727, December, 2017.

[3] Choubey, P.N., Hong, W., Hao, Z.C., Chen, P., Duong, T.V., and Mei, J., "A Wideband Dual-Mode SIW CavityBacked Triangular-Complimentary-Split-Ring-Slot (TCSRS) Antenna", IEEE Transaction on Antennas and Propagation, Volume 64, No. 6, pp. 2541-2545, June, 2016.

[4] Hussain, R., Alreshaid, A.T., Podilchak, S.K., and Sharawi, M.S., "A Compact 4G MIMO Antenna Integrated with a 5G Array for Current and Future Mobile Handsets", IET Microwaves, Antennas \& Propagation, Volume 11, No. 2, pp. 271-279, January, 2017.

[5] Aliakbari, H., Abdipour, A., Costanzo, A., Masotti, D., Mirzavand, R., and Mousavi, P., "ANN-Based Design of a Versatile Millimetrewave Slotted Patch Multi-Antenna Configuration for 5G Scenarios", IET Microwaves, Antennas \& Propagation, Volume 11, No. 9, pp. 1288-1295, June, 2017.

[6] Park, S.J., Shin, D.H., and Park, S.O., "Low Side-Lobe Substrate-Integrated-Waveguide Antenna Array Using Broadband Unequal Feeding Network for mmWave Handset Device", IEEE Transactions on Antennas and Propagation, Volume 64, No. 3, pp. 923-932, March, 2016. 

Concerning mmWave Phased Array in Mobile Devices for 5G Communication", IEEE Antennas and Wireless Propagation Letters, Volume 15, pp. 1132-1135, October, 2015.

Dadgarpour, A., Sorkherizi, M.S., and Kishk, A.A., "Wideband, Low-Loss Magneto-Electric Dipole Antenna for 5G Wireless Network with Gain Enhancement Using Meta Lens and Gap Waveguide Technology Feeding", IEEE Transactions on Antennas and Propagation, Volume 64, No. 12, pp. 5094-5101, December, 2016.

Dzagbletey, P.A., Kim, K.S., Byun, W.J., and Jung, Y.B., "Stacked Microstrip Linear Array with Highly Suppressed Side-Lobe Levels and Wide Bandwidth", IEEE Transactions on Antennas and Propagation, Volume 65, No. 12, pp. 6317-6328, December, 2017.

[10] Zhang, S., Chen, X., Syrytsin, I., and Pedersen, G.F., “A Planar Switchable 3D-Coverage Phased Array Antenna and Its User Effects for $28 \mathrm{GHz}$ Mobile Terminal Applications", IEEE Transactions on Antennas and Propagation, Volume 65, No. 12, pp. 6413-6421, December, 2017.

[11] Chen, W., Balanis, C.A., and Birtcher, C.R., "Dual WideBand Checkerboard Surfaces for Radar Cross Section Reduction", IEEE Transaction of Antennas and Propagation, Volume 64, No. 9, pp. 4133-4138, September, 2016.

[12] Elfrgani, A.M., "Relativistic BWO with Gaussian Radiation Radially Extracted Using an Electromagnetic Bandgap Medium", IEEE Transactions on Plasma Science, Volume 44, No. 2, pp. 152-156, February, 2016.

[13] Li, Q., Feresidis, A.P., Mavridou, M., and Hall, P.S., "Miniaturized Double-layer EBG Structures for Broadband Mutual Coupling Reduction between UWB Monopoles", IEEE Transactions on Antennas and Propagation, Volume 63, No. 3, pp. 1168-1171, March, 2015.

[14] Lai, H.W., Luk, K.M., and Leung, K.W., "Dense Dielectric Patch Antenna A New Kind of Low-Prole Antenna Element for Wireless Communications", IEEE Transactions on Antennas and Propagation, Volume 61, No. 8, pp. 4239 - 4245, August, 2013.

[15] Elboushi, A., Briqech, Z., and Sebak, A., "4-Elements MMW Array with EBG Feeding Network”, Proceeding of IEEE Internation Symposium of Antennas Propagations, pp. 162-163, July, 2013.

[16] Kishk, A.A., "DRA-Array with $75 \%$ Reduction in Elements Number", Proceedings of IEEE Radio Wireless Symposium, pp. 70-72, January, 2013.
Al-Tari, M.A., Anagnostou, D.E., Amert, A.K., and Whites, K.W., "Bandwidth Enhancement of the Resonant Cavity Antenna by Using Two Dielectric Superstrates", IEEE Transactions on Antennas and Propagation, Volume 61, No. 4, pp. 1898-1908, April, 2013.

[18] Malekpoor, H., and Jam, S., "Improved Radiation Performance of Low Profile Printed Slot Antenna Using Wideband Planar AMC Surface", IEEE Transactions on Antennas and Propagation, Volume 64, No. 11, pp. 4626-4638, November, 2016.

[19] Liang, B., Sanz-Izquierdo, B., Parker, E.A., and Batchelor, J.C., "A Frequency and Polarization Reconfigurable Circularly Polarized Antenna Using Active EBG Structure for Satellite Navigation", IEEE Transactions on Antennas and Propagation, Volume 63, No. 1, pp. 33-40, January, 2015.

[20] Ruiz, J.D.D., Martínez, F.L., and Hinojosa, J., "Novel Compact Wide-Band EBG Structure Based on Tapered 1D Koch Fractal Patterns", IEEE Antennas and Wireless Propagation Letters, Volume 10, pp. 1104-1107, 2011.

[21] Zhu, H., and Mao, J., "Miniaturized Tapered EBG Structure With Wide Stopband and Flat Passband", IEEE Antennas and Wireless Propagation Letters, Volume 11, pp. 314-317, 2012.

[22] Al-Hasan, M.J., Denidni, T.A., and Sebak, A.R., "Millimeter-Wave Compact EBG Structure for Mutual Coupling Reduction Applications", IEEE Transaction on Antennas and Propagation, Volume 63, No. 2, pp. 823-828, February, 2015.

[23] Arnaud, E., Chantalat, R., Koubeissi, M., Monediere, T., Rodes, E., and Thevenot, M., "Global Design of an EBG Antenna and Meander-Line Polarizer for Circular Polarization", IEEE Antennas and Wireless Propagation Letters, Volume 9, pp. 215-218, 2010.

[24] Arnaud, E., Chantalat, R., Monediere, T., Rodes, E., and Thevenot, M., "Performance Enhancement of SelfPolarizing Metallic EBG Antennas", IEEE Antennas and Wireless Propagation Letters, Volume 9, pp. 538-541, 2010 .

[25] Ceccuzzi, S., Pajewski, L., Ponti, C., and Schettini, G., "Directive EBG Antennas: A Comparison Between Two Different Radiating Mechanisms", IEEE Transactions on Antennas and Propagation, Volume 62, No. 10, pp. 5420-5424, October, 2014.

[26] Cao, W., Zhang, B., Liu, A., Yu, T., Guo, D., and Pan, X., "Multi-Frequency and Dual-Mode Patch Antenna Based on Electromagnetic Band-GapStructure", IEEE Transactions on Antennas and Propagation, Volume 60, No. 12, pp. 6007-6012, December, 2012.

[27] Balanis, C.A., "Antenna Theorey Analysis and Design", John Wiley \& Sons, Inc., Hoboken, New Jersey, 2005. 